\title{
The Brugada Syndrome: A Rare Arrhythmia Disorder with Complex Inheritance
}

\author{
Jean-Baptiste Gourraud 1, 2,3,4, Julien Barc ${ }^{2,3,4}$, Aurélie Thollet ${ }^{1}$, Solena Le Scouarnec ${ }^{2,3,4}$ \\ Hervé Le Marec ${ }^{1,2,3,4}$, Jean-Jacques Schott ${ }^{1,2,3,4}$, Richard Redon ${ }^{1,2,3,4}$ and \\ Vincent Probst ${ }^{1,2,3,4 *}$

\begin{abstract}
${ }^{1}$ Service de Cardiologie, Centre Hospitalier Universitaire (CHU) de Nantes, I'institut du thorax, Nantes, France, ${ }^{2}$ Institut National de la Santé et de la Recherche Médicale (INSERM) Unité Mixte de Recherche (UMR) 1087, l'institut du thorax, Nantes, France, ${ }^{3}$ Centre National de la Recherche Scientifique (CNRS) UMR 6291, l'institut du thorax, Nantes, France, ${ }^{4}$ l'institut du thorax, Université de Nantes, Nantes, France
\end{abstract}

For the last 10 years, applying new sequencing technologies to thousands of whole exomes has revealed the high variability of the human genome. Extreme caution should thus be taken to avoid misinterpretation when associating rare genetic variants to disease susceptibility. The Brugada syndrome (BrS) is a rare inherited arrhythmia disease associated with high risk of sudden cardiac death in the young adult. Familial inheritance has long been described as Mendelian, with autosomal dominant mode of transmission and incomplete penetrance. However, all except 1 of the 23 genes previously associated with the disease have been identified through a candidate gene approach. To date, only rare coding variants in the SCN5A gene have been significantly associated with the syndrome. However, the genotype/phenotype studies conducted in families with SCN5A mutations illustrate the complex mode of inheritance of $\mathrm{BrS}$. This genetic complexity has recently been confirmed by the identification of common polymorphic alleles strongly associated with disease risk. The implication of both rare and common variants in BrS susceptibility implies that one should first define a proper genetic model for BrS predisposition prior to applying molecular diagnosis. Although long remains the way to personalized medicine against BrS, the high phenotype variability encountered in familial forms of the disease may partly find an explanation into this specific genetic architecture.

Keywords: Brugada syndrome, genetics, sudden death, cardiac arrhythmias, SCN5A

\section{INTRODUCTION}

The Brugada syndrome (BrS) is a rare inherited arrhythmia disease, first described in 1992, increasing the risk of ventricular fibrillation in apparently healthy young adults (1). It is suspected to be involved in $4-12 \%$ of cases of sudden cardiac death (SCD) in the general population and in at least $20 \%$ of SCD in patients with a structurally normal heart (1-3).

Clinical diagnosis is based on a specific electrocardiographic (ECG) pattern defined in three consecutive consensus conferences (4-6). This ECG pattern, previously known as "type 1" ECG pattern, is defined as a ST segment elevation with a coved-type morphology $\geq 0.2 \mathrm{mV}$ in one lead among the right precordial leads V1 and V2, positioned in the second, third, or fourth intercostal space occurring either spontaneously or after provocative drug test with intravenous administration of Class I antiarrhythmic drugs (6) (Figure 1). The ECG pattern may be transient in affected 
patients (7). To address this issue, unmasking drugs, such as ajmaline, flecainide, and procainamide, can be used to reveal this pattern (8), ajmaline showing higher sensitivity than flecainide and procainamide $(4,9,10)$.

The high variability of the ECG pattern impairs proper assessment of its prevalence in the general population. Epidemiological studies have produced heterogeneous results regarding $\mathrm{BrS}$ incidence across the World. While estimated at 5 for 10,000 in western Europe and the USA, the prevalence of BrS seems higher in Southeast Asia, reaching 20 for 10,000 (11-13).

Aborted SCD is often the first symptom in BrS, with a mean age of 45 years at diagnosis and a four-time higher incidence in men than in women $(14,15)$. A third of the affected patients are identified after syncope, frequently preceded by vagal symptoms (14). The syncope could either be due to non-sustained VF or to a vaso-vagal episode without direct clinical relevance, rendering it hard for the practitioner to distinguish arrhythmic from non-arrhythmic etiology $(16,17)$. The majority of patients are asymptomatic at time of diagnosis. More than one-third of cases are identified during familial screening (14).
Implantation of a defibrillator is still the only efficient therapy in high-risk patients, with a $48 \%$ rate of appropriate device therapy at 10 years in patients with previous aborted sudden death. This rate falls to $12 \%$ among implanted asymptomatic patients, many affected patients remaining asymptomatic during all their life. Furthermore, device-related complications are frequent with a $30 \%$ risk at 10 -year follow-up mainly due to lead dysfunction, inappropriate therapy, and infection $(18,19)$. These serious side effects in comparison to the very low arrhythmic risk for asymptomatic patients require accurate risk stratification and/ or efficient drug therapy.

Only few clinical parameters allow risk stratification in BrS. The effectiveness of ventricular stimulation is still a matter of debate, and symptoms and spontaneous ECG pattern are still the two major parameters enabling risk stratification for $\operatorname{SCD}(6,14,20-23)$.

There is still need for medical therapies that could reduce arrhythmia occurrence and prevent SCD. Because successful trials were reported in limited series of patients, quinidine has been expected to be "the drug" for BrS. However, several recent studies failed to demonstrate its beneficial effects $(6,24-27)$.
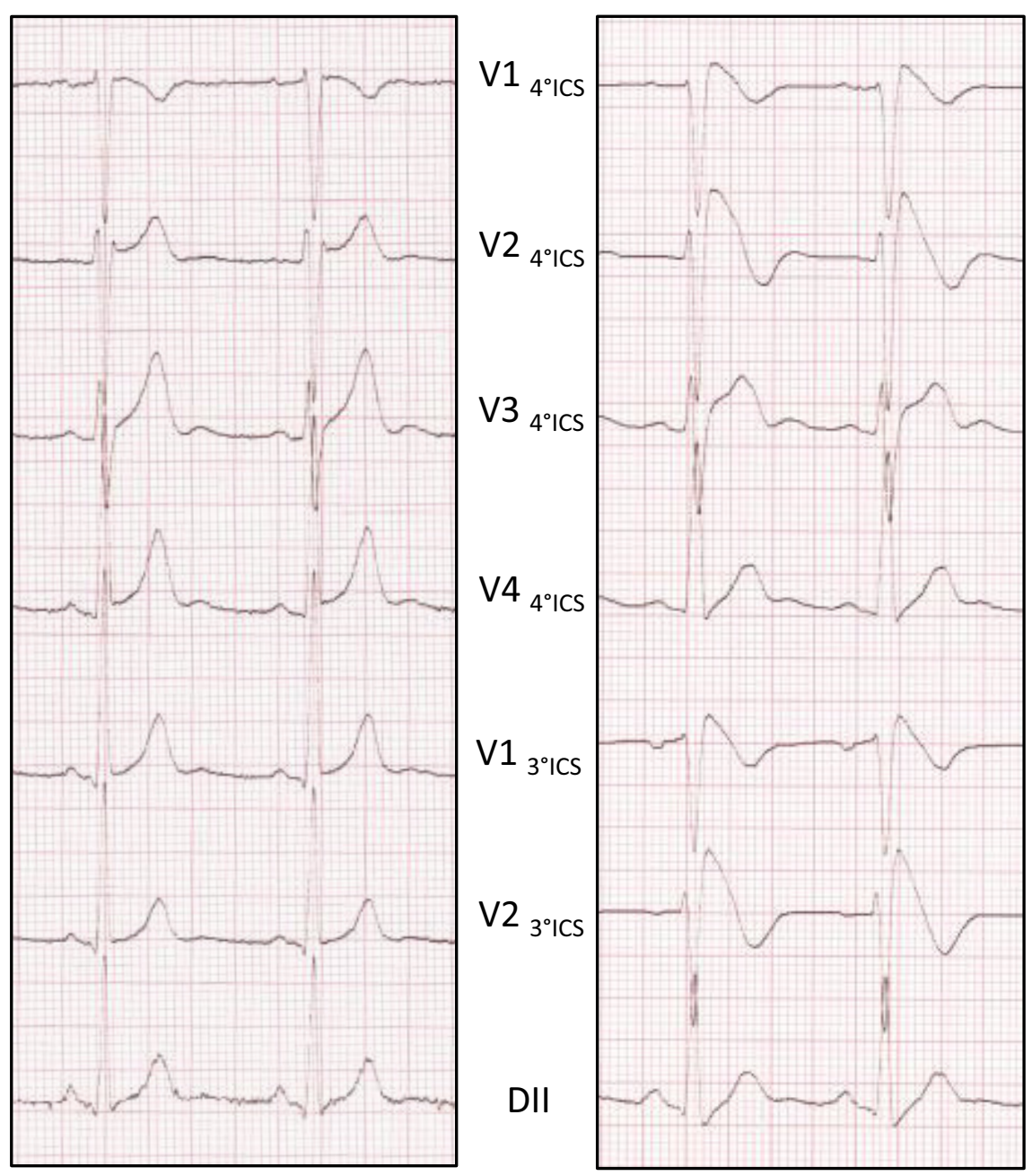

FIGURE 1 | Ajmaline testing reveals the Brugada ECG pattern. ECG pattern is recorded at $1 \mathrm{~mm} / 10 \mathrm{mV}$ and $25 \mathrm{~mm} / \mathrm{s}$. Baseline ECG without aspect of BrS (left side). Type 1 Brugada pattern on the right precordial leads at the end of the test (right side). 
There is accumulating evidence that implantable defibrillator is an effective and accurate therapy for symptomatic patients (18). Many clinical parameters have also been proposed for asymptomatic patients, but risk prediction in the latter group of patients remains particularly challenging because of the lack of reproducible and reliable data (28).

\section{TWO PATHOPHYSIOLOGICAL MODELS FOR BrS}

Those unresolved questions concerning diagnosis and risk stratification for arrhythmia and therapy underlie the need for a better understanding of pathophysiological mechanisms in BrS. Two main pathophysiological hypotheses have been proposed to explain the ECG pattern.

Soon after the description of BrS, the first pathophysiological model was proposed, based on the existence of a transmural voltage gradient due to a repolarization heterogeneity across the ventricular wall $(29,30)$. According to this hypothesis, ST segment elevation could be due to either a loss of function of the sodium channel NaV1.5 responsible for the depolarization phase (phase 0 of the AP) favoring the expression of repolarization heterogeneity, an aggravation of this heterogeneity by a gain of function in one of the cardiac potassium channels responsible of the repolarization phases (phases 1 and 3 of the AP), or a loss of function of the CaV1.2 calcium channel that participate to the phase 2 of the AP (29).

This hypothesis has been matter to debate since the second hypothesis, based on a conduction delay in the right ventricular outflow tract, emerged from clinical observations (31-35). This conduction delay could be responsible for voltage gradients between RV and RVOT during and explain the BrS ECG pattern.

Twenty years of genetic research based on both technological and methodological progresses have started to depict the complexity of BrS pathophysiology $(36,37)$. This review aims to provide an integrated synopsis of those two decades of research and to suggest future directions for further genetic investigations against BrS.

\section{FROM A FAMILIAL DISEASE TO THE IDENTIFICATION OF RARE VARIANTS}

With the initial report of two affected siblings, familial inheritance was suggested from the first description of the Brs in 1992 (1). Few years later, Kobayashi et al. described a two-generation family presenting with both SCD and persistent ST elevation in relatives (38), confirming the heritability of the disease. The genetic component of $\mathrm{BrS}$ was further demonstrated in several reports (39-41) (Figure 2). Today, familial history of SCD is

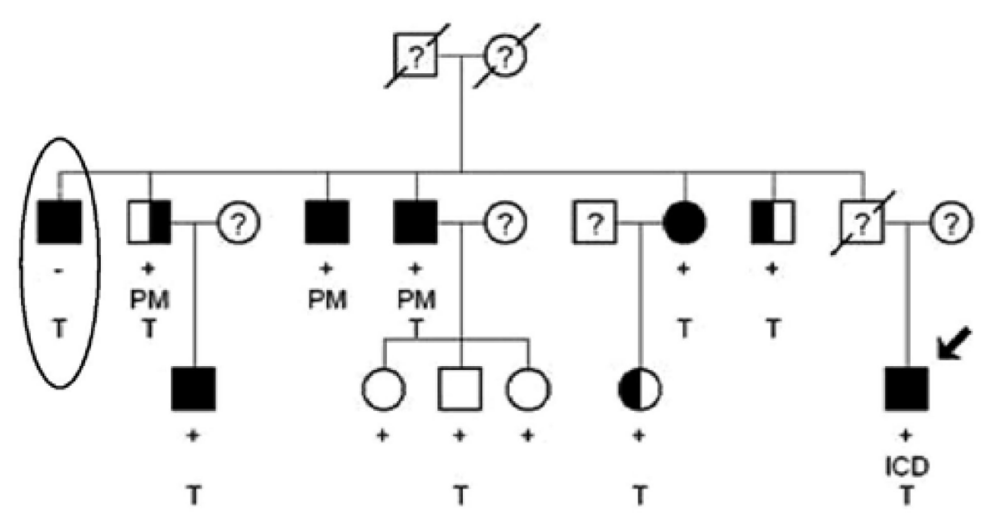

Clinical status

Additionnal information

Brs D Affected

$\boldsymbol{\kappa}$ Proband

PCCD Affected

ICD Implantable Cardiac Defibrillator

PM Pacemaker

$\mathrm{T}$ Test performed (Na channel blocker)

Genetic status (SCN5A mutation)

+ Carrier

- Non-Carrier

FIGURE 2 | The complex inheritance pattern of BrS. Modified from Ref. (41). Incomplete penetrance of the SCN5A mutation is illustrated by the presence of unaffected carriers of the mutation (+). The patient highlighted by an ellipse presents with a BrS ECG aspect, despite the absence of the familial mutation. Affected family members carrying the SCN5A mutation present with progressive cardiac conduction disease (PCCD) (right half-filled symbol), BrS (left half-filled symbol), or both diseases (full-filled symbol). PCCD consists of right bundle branch block with PR interval lengthening and led to complete AVB in three patients, in whom a pacemaker (PM) was implanted. 
reported for about $26 \%$ of affected patients. Additionally, $36 \%$ of affected patients are identified during familial screening after SCD or identification of BrS in the proband (14).

Brugada syndrome has been consistently reported as a monogenic disease with autosomal dominant mode of inheritance, caused by rare genetic variants with large effect size $(1,38)$. Loss-of-function mutations in the SCN5A-encoded $\alpha$-subunit of the cardiac sodium channel (Nav1.5) were first identified in 1998 (42). Mutations in SCN5A are detected in 20-25\% of cases, SCN5A appearing as the major susceptibility gene for BrS (43). More than 300 rare variants in SCN5A have been reported, while the contribution of other genes remains extremely low $(43,44)$. In a pediatric population affected by BrS, the prevalence of SCN5A mutations seems to be even higher (45).

In this context, genetics was initially expected to help the clinical management of patients with BrS. Although some SCN5A mutations - particularly those leading to premature truncation of Nav1.5 - have been reported as associated with higher arrhythmic risk, no such result has been further confirmed in randomized studies (14, 46-48).

Despite evidence for strong familial inheritance, familial linkage analyses on BrS have been largely unsuccessful. Only one gene, GPD1L, has been identified as a BrS-susceptibility gene using this approach (49). The causing mutation in GPD1L has been shown to affect $\mathrm{Na}^{+}$channel trafficking to the plasma membrane, by modifying its oxydation state $(49,50)$. Every other gene reported so far has been identified through a candidate approach based on direct sequencing of genes with a known (or suspected) role in cardiac electrical activity.
So far, 23 genes have been related to BrS (Table 1). Based on pathophysiological hypotheses, those genes can be divided according to whether they affect the sodium current $I_{\mathrm{Na}}(S C N 5 A$, SCN10A, GPD1L, SCN1B, SCN3B, RANGRF, SCN2B, PKP2, $S L M A P$, and FGF12), the potassium current $I_{\mathrm{K}}$ (KCNJ8, KCNH2, KCNE3, KCND3, KCNE5, KCND2, SEMA3A, and ABCC9), or the calcium current $I_{\mathrm{Ca}}(C A C N A 1 C, C A C N B 2 B$, and $C A C N A 2 D 1)$.

\section{LIMITS IN INTERPRETING RARE VARIANTS CARRIED BY PATIENTS WITH BrS}

In the last decade, the emergence of massively parallel sequencing [or next-generation sequencing (NGS)] has considerably facilitated genetic screening and reduced its cost (72-76). Combined to the availability of the reference assembly of the human genome $(77,78)$, NGS-based approaches have revealed the high variability of the human genome, with at least 300-600 functional genetic variants detected in each exome (i.e., the whole coding portion of a single genome) (75) - and has retrospectively changed the interpretation of previous rare variants identified by candidate gene approach. The investigation of large number of exomes revealed the extraordinary prevalence of rare variants among each individual. As an illustration, the sequencing of 60,706 exomes identified about 7,500,000 variants from which $99 \%$ have a frequency of $<1 \%$ (http://biorxiv.org/content/early/2015/10/30/030338).

Extreme caution should thus be taken when interpreting the rare genetic variants detected among patients with $\mathrm{BrS}$, since the

TABLE 1 | The 23 reported susceptibility genes for BrS.

\begin{tabular}{|c|c|c|c|c|c|}
\hline $\begin{array}{l}\text { OMIM } \\
\text { ranking }\end{array}$ & Gene & Protein & $\begin{array}{c}\text { Prevalence in } \\
\text { BrS cases }\end{array}$ & $\begin{array}{l}\text { Functional effect } \\
\text { of the mutation }\end{array}$ & Reference \\
\hline BrS1 & SCN5A & $\alpha$ subunit of the Nav1.5 sodium channel & $20-25 \%$ & $\mathbf{y} / \mathrm{Na}$ & $(42)$ \\
\hline $\mathrm{BrS2}$ & GPD1L & Glycerol-3-phosphate dehydrogenase 1-like & Rare & y $/ /_{\mathrm{Na}}$ & (49) \\
\hline BrS3 & CACNA1C & $\alpha$ subunit $\alpha 1 \mathrm{C}$ of the Cav1.2 calcium channel & $1-2 \%$ & $\mathbf{y} /$ Ca-L & $(51)$ \\
\hline BrS4 & CACNB2b & $\beta$ subunit Cav $\beta 2 b$ of calcium channel & $1-2 \%$ & $\mathbf{y} /$ Ca-L & $(51)$ \\
\hline BrS5 & SCN1b & $\beta$ subunit $N a v \beta 1$ of sodium channel & Rare & $\mathbf{y} / \mathrm{Na}$ & $(52)$ \\
\hline BrS6 & KCNE3 & $\beta$ subunit MiRP2 of potassium channel & Rare & $\boldsymbol{\lambda} l_{\text {to }}$ & (53) \\
\hline $\mathrm{BrS7}$ & $S C N 3 b$ & $\beta$ subunit Nav $\beta 3$ of sodium channel & Rare & $\boldsymbol{y} / \mathrm{Na}$ & $(54)$ \\
\hline BrS8 & HCN4 & Hyperpolarization-activated cyclic nucleotide-gated channel 4 & Rare & $?$ & $(55)$ \\
\hline BrS9 & KCND3 & $\alpha$ subunit of the KV4.3 potassium channel & Rare & $\boldsymbol{\lambda} I_{\text {to }}$ & $(56)$ \\
\hline $\mathrm{BrS10}$ & KCNJ8 & $\alpha$ subunit of the KIR6.1 potassium channel & Rare & $\boldsymbol{\pi} /$ KATP & $(57)$ \\
\hline BrS11 & CACNA2D1 & $\delta$ subunit Cav $\alpha 2 \delta 1$ of calcium channel & Rare & $\boldsymbol{y} / I_{\text {Ca-L }}$ & $(58)$ \\
\hline $\mathrm{BrS12}$ & KCNE5 & $\beta$ subunit of potassium channel & Rare & $\boldsymbol{\pi} I_{\text {to }}$ & $(59)$ \\
\hline $\mathrm{BrS13}$ & RANGRF & RAN guanine nucleotide release factor & Rare & $\boldsymbol{y} / \mathrm{Na}$ & $(60)$ \\
\hline BrS14 & KCND2 & $\alpha$ subunit of the KV4.2 potassium channel & Rare & $\boldsymbol{\gamma} I_{\text {to }}$ & $(61)$ \\
\hline BrS15 & TRPM4 & Calcium-activated non-selective ion channel & Rare & $?$ & $(62)$ \\
\hline BrS16 & $S C N 2 B$ & $\beta$ subunit $N a v \beta 2$ of sodium channel & Rare & $\boldsymbol{y} / I_{\mathrm{Na}}$ & (63) \\
\hline $\mathrm{BrS17}$ & PKP2 & Plakophilin 2 & Rare & $\boldsymbol{y} / \mathrm{Na}$ & $(64)$ \\
\hline $\mathrm{BrS18}$ & ABCC9 & ATP-sensitive potassium channels & Rare & $\boldsymbol{\lambda} /$ KATP & $(65)$ \\
\hline BrS19 & SLMAP & Sarcolemma-associated protein & Rare & $\mathbf{y} / \mathrm{Na}$ & (66) \\
\hline BrS20 & $\mathrm{KCNH} 2$ & $\alpha$ subunit of the HERG potassium channel & Rare & $\boldsymbol{\lambda} I_{\mathrm{Kr}}$ & $(67)$ \\
\hline $\mathrm{BrS} 21$ & SCN1OA & $\alpha$ subunit of the Nav1.8 sodium channel & $<5 \%$ & $\boldsymbol{y} / \mathrm{Na}$ & $(68,69)$ \\
\hline $\mathrm{BrS} 22$ & FGF12 & Fibroblast growth factor 12 & Rare & $\boldsymbol{y} / \mathrm{Na}$ & $(70)$ \\
\hline $\mathrm{BrS} 23$ & SEMA3A & Semaphorin family protein & Rare & $\boldsymbol{\gamma} I_{\text {to }}$ & $(71)$ \\
\hline
\end{tabular}

Functionnal effect on current are described with arrow, except for HCN4 mutation for which it remain unclear (?). 
clinical implication of finding those variants remains doubtful in the absence of statistical association and/or of evidence supporting a functional effect in relation with cardiac electrical activity (79-82).

Furthermore, a recent study has illustrated the weakness of candidate approaches on small pedigrees, by highlighting the high frequency of some genetic variants previously associated with BrS among 6,500 individual exomes from the Exome Sequencing Project (83). One variant in particular, which was related to $\mathrm{BrS}$ based on functional evidence, showed a minor allele frequency of $4.4 \%$ among the 6,500 individuals. This result was confirmed in a healthy Danish control population, suggesting that a proportion of the genetic variants reported as causing BrS are actually not pathogenic. Interestingly, $93 \%$ of the SCN5A variants reported as causing $\mathrm{BrS}$ are not present among the control population, thus reinforcing the pivotal role of this gene.

By testing the burden of rare coding variants in 45 arrhythmiasusceptibility genes among $167 \mathrm{BrS}$ cases versus 167 control individuals, we have also recently demonstrated the limitation of previous candidate approaches (44). Indeed, for every tested gene except $S C N 5 A$, rare variants were found in the same proportion in cases than in controls. Figure 3 shows the distribution of rare variants among cases and controls for the protein products of four genes: SCN5A, SCN10A, CACNA1C, and PKP2. The distribution of rare variants across the functional domains of the CACNA1C product indicates that the $\mathrm{C}$-terminal tail, which was previously considered as pathogenic in BrS, may in fact be highly polymorphic. On the opposite, most rare variants detected along the protein encoded by $P K P 2$ among BrS patients reside in a small interval coding for four amino acids. The PKP2 gene has been previously associated with BrS by decreasing functional Na channel expression through modification of microtubule anchoring (64). The small PKP2 interval emphasized in this study may be a preferential site of such interaction.
Rare genetic variants appear more evenly distributed across $S C N 10 A$ and less predictive of any potential pathophysiological mechanism. In fact, the functional effects of these rare variants affecting SCN10A are largely debated. SCN10A gene, which encodes the sodium channel $\mathrm{Na}_{\mathrm{v}} 1.8$, was initially described in neurons physiology $(84,85)$. Further investigations illustrated a potential role in cardiac electrophysiology, particulary as a modulator of cardiac conduction $(86,87)$. Recently, Hu et al. described rare variants in the SCN10A gene, in $16.7 \%$ of 150 patients affected with BrS (68). Furthermore, they demonstrated that the SCN10A variants R1268Q and R14L reduced cardiac sodium currents (68). However, although relevant biological effects are reported for some variants, most variants are also reported in control populations. Behr et al. have recently underlined this issue (69). Using an extended control population, they decreased the yield of such variants from $16.7 \%$ in the $\mathrm{Hu}$ et al's study to $5.1 \%$ in a different set of BrS probands (68). Additionally, only two over seven familial pedigrees available with such variants demonstrated segregation with the BrS.

Coding genetic variants in candidate genes are usually classified as likely pathogenic if they are extremely rare or absent from control populations. However, private genetic variants are found in control populations, and many rare variants predicted as damaging are carried by apparently healthy individuals $(44,83)$. As an example, in the SCN5A gene, rare functional variants can be found in about $2 \%$ of control patients and even in $5 \%$ in non-white population (88). Thus, considering SCN5A-mediated $\mathrm{BrS}$ account for about $20 \%$ of cases and that background noise of rare variant with minor allele frequency under $1 / 10,000$ is approximately $2 \%$, there is a $10 / 1$ signal to noise ratio that means a $10 \%$ risk of false positive in possibly damaging rare SCN5A variants (82). As prevalence of asymptomatic BrS in the general population is unknown, this percentage may be over estimated. However, as $\mathrm{BrS}$ is a rare disease, the proportion of false positive

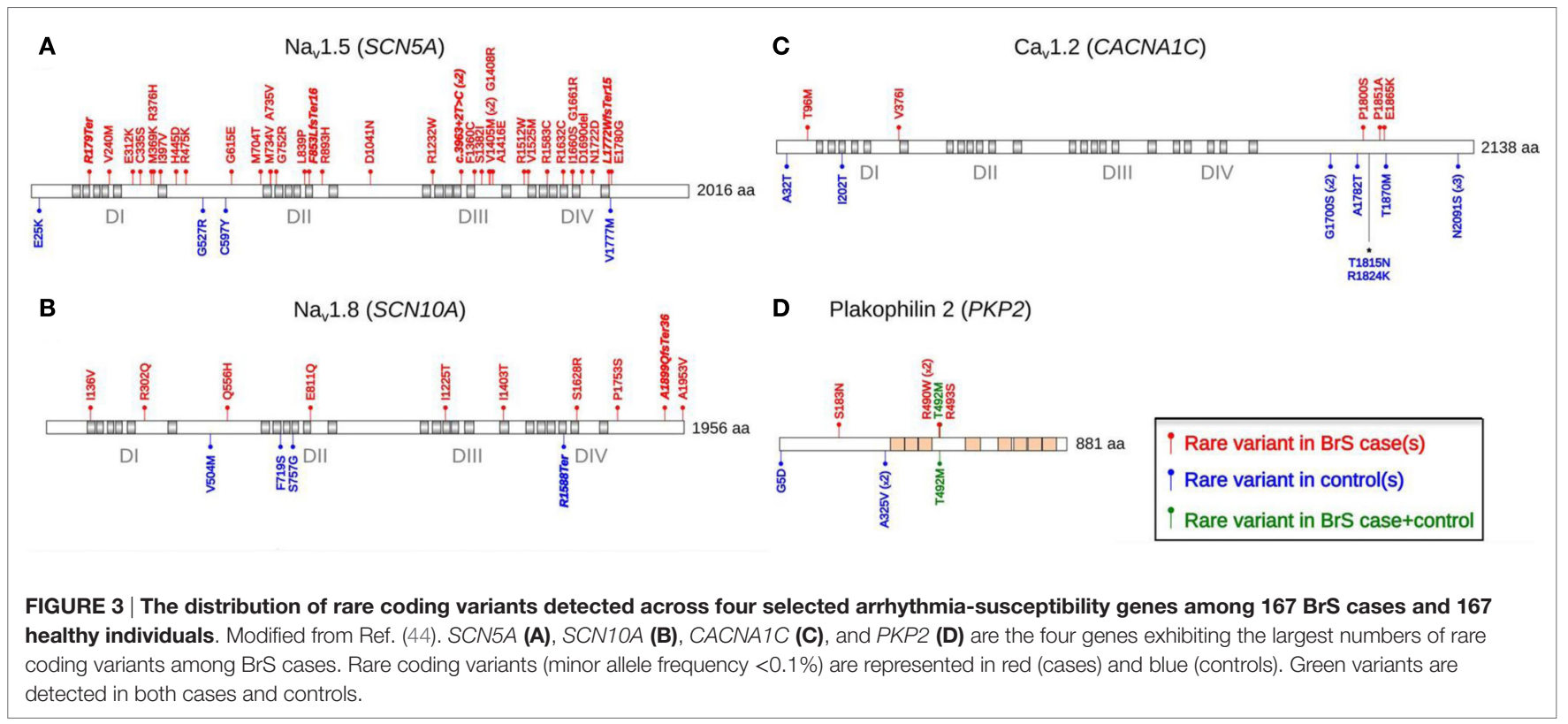


variants remains, in any case, too high to be confident with a direct translation of new rare variants in clinical practice.

On the opposite, some rare variants detected among $\mathrm{BrS}$ patients are reported as benign by prediction algorithms though they modify the function of the protein. As an example, while one $S C N 3 B$ variant has been associated with $\mathrm{BrS}$ and reported as impacting the sodium current density, it is considered as benign by prediction algorithms such as SIFT and PolyPhen-2 (54, 89, 90). This demonstrates the strong limitations of such prediction algorithms and the need for functional studies and/or segregation analyses to better assess the causality of rare variants.

From that perspective, mutations in L-type calcium channels (CACNA1C, CACNB2B, and CACNA2D1) that were considered as associated with about $4 \%$ of $\mathrm{BrS}$ cases are of particular interest (43). The L-type calcium current $I_{\mathrm{Ca}-\mathrm{L}}$ is a perfect candidate to explain BrS physiopathology, due to its central role in action potential dome (phases 2 and 3) and in the "depolarization" hypothesis (91). However, functional studies on mutations in L-type calcium channels are scarce in the literature. Moreover, mutations in CACNA1C among BrS cases and controls are mostly located within the $\mathrm{C}$-terminal tail of $\mathrm{Ca}_{\mathrm{v}} 1.2$, thus suggesting a high genetic variability of the domain (Figure 3). Although CACNA1C mutations seem to play lesser role than previously reported, this particular gene remains involved in a small subset of $\mathrm{BrS}$ cases, in particularly those with combined phenotypes of $\mathrm{BrS}$ and short QT syndrome (92).

These accumulated data demonstrate that in order to avoid misinterpretation of genetic variants: (1) functional prediction algorithms should be used cautiously and (2) ancestry-matched control populations should be systematically considered. Furthermore, familial segregation analysis and/or extended functional testing are mandatory before associating rare coding variants to disease susceptibility.

Following these guidelines, no previously reported susceptibility gene except SCN5A seems to contribute significantly to $\mathrm{BrS}$ pathophysiology. Although SCN5A remains the major gene involved in BrS with about $20 \%$ of carriers among probands $(43,44)$, a proportion of rare variants residing in this gene - particularly among those of uncertain functional effect - could play no role in relation with the disease (82).

\section{THE COMPLEX INHERITANCE OF BrS: TOWARD A NEW GENETIC MODEL}

Since the discovery of SCN5A as the first susceptibility gene for $\mathrm{BrS}$, this disorder has been consistently reported as a monogenic disease with autosomal dominant mode of inheritance, caused by rare genetic variants with large effect size $(1,38,42)$. SCN5A remains the only major susceptibility gene for $\mathrm{BrS}$, with more than 300 coding variants described among more than $75 \%$ of the genetically diagnosed patients $(43,93)$. However, hardly any of the large family pedigrees with $\mathrm{BrS}$ provides evidence for Mendelian inheritance. Most familial forms indicate a genetic model with incomplete penetrance and remain genetically undiagnosed.

We have investigated the cosegregation of SCN5A mutations with $\mathrm{BrS}$ among large genotyped families (41). SCN5A mutations exhibit low penetrance (61\% after drug testing) in families, leading to poor genotype/phenotype correlations. More surprisingly, among five pedigrees, we could identify eight affected members who did not carry the familial SCN5A mutation (Figure 2). This lack of genotype/phenotype correlation is further emphasized in other families with variable cardiac phenotypes associated with a same SCN5A mutation. Indeed, although a Na current decrease could lead to cardiac conduction or sinus node dysfunction, the description of relatives sharing the same SCN5A mutation but presenting with either BrS or a progressive cardiac conduction disease question about the relevance of a monogenic model $(94,95)$. A similar issue involving SCN5A mutation has been described with BrS and long QT syndrome (96).

These observations have led us to seek for genetic factors modulating the risk of Brugada ECG phenotype. To explore the potential role of common genetic variants in susceptibility to Brs, we have recently coordinated an international genomewide association study (GWAS) on BrS. By comparing allele frequencies of common haplotypes genome wide among 312 index cases versus 1,115 control individuals, we identified three loci associated with susceptibility to BrS (Figure 4A). The three hits were then replicated on independent case-control sets from Europe and Japan. We found that their cumulative effect on disease susceptibility was unexpectedly large, with an estimated odds ratio of 21.5 in the presence of more than four risk alleles versus less than two (Figure 4B). This study demonstrates that an aggregation of genetic polymorphisms can strongly influence the susceptibility to BrS and confirms that the mode of inheritance for this arrhythmia disorder is far more complex than previously described.

Two association signals reside at the SCN5A-SCN10A locus. Both common risk alleles have previously been associated with cardiac conduction traits in the general population (97). This finding demonstrates that genetic polymorphisms modulating cardiac conduction can also influence susceptibility to cardiac arrhythmia. One haplotype is located inside the SCN10A gene, of which involvement in the pathophysiology of $\mathrm{BrS}$ is still matter to debate. van den Boogaard et al. provided evidence that the SCN10A haplotype contain was an enhancer region for both SCN10A and SCN5A genes (98). They further demonstrated that a common variant (rs6801957) of this locus, associated with cardiac conduction trait and in high linkage disequilibrium with rs10428132, alters a transcription factor binding site for TBX3/TBX5 and reduces the SCN5A expression (99). This may explain the high phenotype variability observed in BrS patients even within a same family.

The third association signal resides near the Hey2 gene, which encodes a basic helix-loop-helix transcriptional repressor expressed in the cardiovascular system. The implication of this gene in susceptibility to BrS was previously unknown (100). Interestingly, Hey2 presents a gradient of expression across the ventricular wall in mirror image with $S C N 5 A$ expression suggesting a possible (indirect) regulation mechanism. Despite no ECG changes, Hey2 heterozygous knockout mice $\left(\mathrm{Hey}^{+/-}\right.$) present interesting findings for BrS pathophysiology. Conduction velocity seems specifically increase in the right outflow tract in which cellular action potential present both increase in AP upstroke 

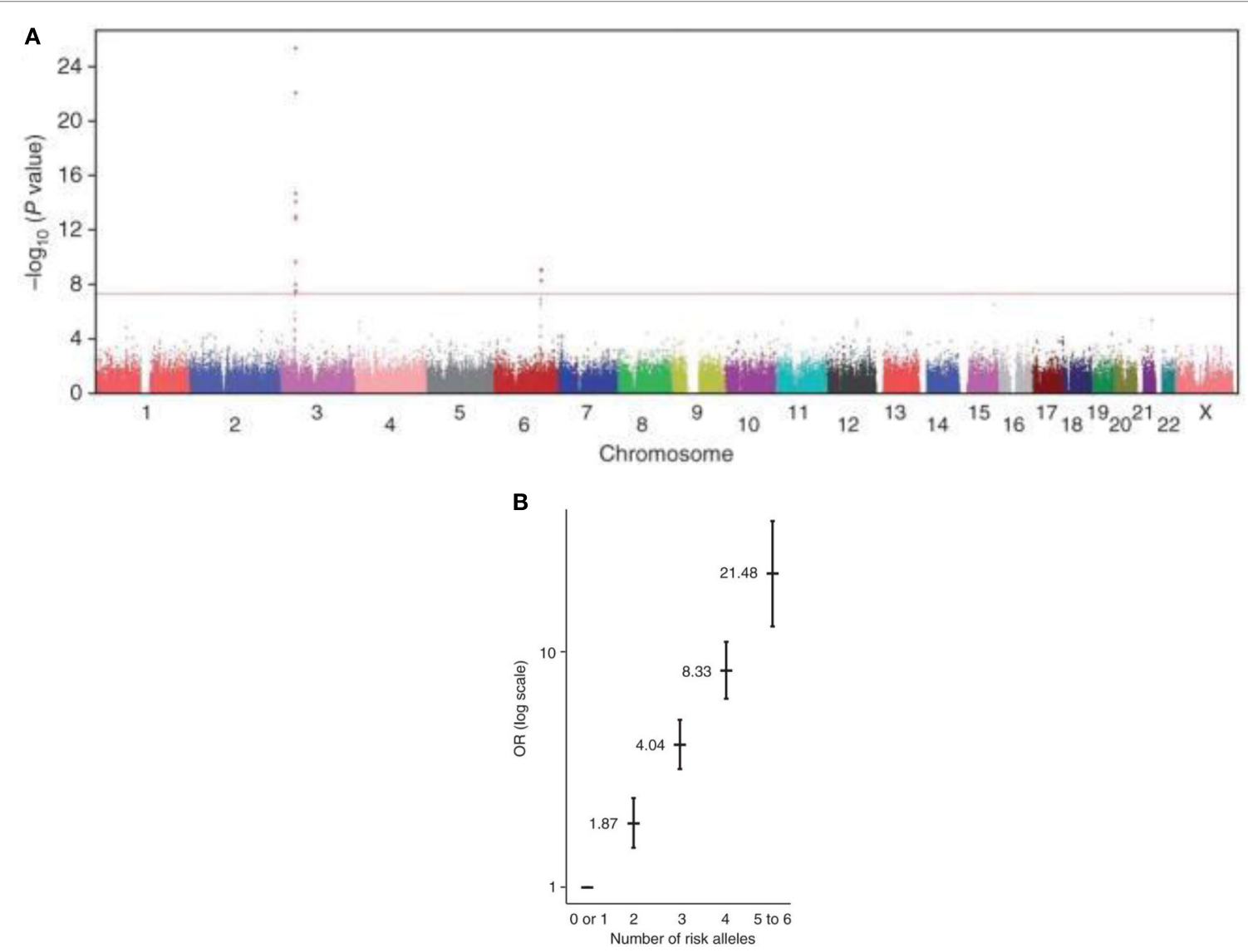

FIGURE 4 | A genome-wide association study on BrS. Modified from Ref. (101). (A) Manhattan plot revealing signal associations between two SNP (SCN10A and HEY2) and BrS. Statistical significance is represented with a red line $\left(P=5 \times 10^{-8}\right)$. A third haplotype of SCN5A reached genome-wide significance after replication analysis. (B) The cumulative effect of the six common risk alleles on susceptibility to BrS. Odds Ratio (OR) is plotted on the vertical axis and the cumulative number of alleles (from 0 to 6 ) in horizontal axis.

velocity and repolarization (101). These data uncovered the role of Hey2 in the cardiac electrical function and more specifically in the pathogenesis of BrS. Among its role on BrS phenotype, common variant in this gene could also presented with a protective role from ventricular fibrillation in BrS patients by regulating the repolarization current (102).

\section{CONCLUSION}

Almost two decades ago, the first description of a mutation in $S C N 5 A$ gene has paved the way of genetics in BrS. As BrS was initially described as a Mendelian disease with low penetrance, many studies have been performed to track genetic variants in families affected by this syndrome. However, in most cases, studies were unable to show positive linkage. In a very large majority of cases, putative causing genes were identified through a "candidate gene approach" based on pathophysiological hypotheses. In these a priori approaches, the results were "validated" by the rarity of the genetic variants identified, while aberrant linkage results were "explained" by non-penetrance or phenocopies.
In the recent years, NGS technologies have dramatically expanded our capacity to sequence genomes. It has also revealed the high variability of the human genome, underlying the extreme caution that should be taken to avoid misinterpretation of the potential association of rare variants with BrS. Thus, recent burden tests have questioned the implication of several genes previously identified as there distribution was similar in the normal population and affected patients. For now, only rare variants in SCN5A gene seem to be significantly associated with the syndrome.

However, genotype/phenotype studies among BrS families with SCN5A mutation carriers have highlighted a complex mode of inheritance for this syndrome. In line with these reports, a GWAS has recently identified three common risk haplotypes for the Brugada ECG pattern.

It is now established that the molecular mechanisms leading to BrS involve both rare and common genetic variants, underlying the need for better understanding the genetic architecture of BrS prior to applying genetics as a diagnostic tool. For the next future, one of the challenges that could contribute to a more efficient 
strategy for BrS would be to decipher the role of the combination of variants both for diagnosis and prognosis.

Another source of progress regarding risk stratification among $\mathrm{BrS}$ patients could go through the identification of specific ECG indices associated with higher risk of (fatal) arrhythmia. Genetic variants at the SCN5A, HEY2, and SCN10A loci have been associated with arrhythmia occurrence in independent studies $(47,102$, 103). Integrating such effects toward establishing a global genetic model for BrS is the next step before including genetic testing into the clinical management of BrS.

Besides the direct benefit of this research on the BrS for itself, it appears increasingly that this primary electrical disorder affecting the young adult (with no identifiable structural abnormalities and presenting limited exposure to environment side effect) may represent a relevant model for the identification of markers and mechanism implied into broader common cardiac arrhythmias.

\section{REFERENCES}

1. Brugada P, Brugada J. Right bundle branch block, persistent ST segment elevation and sudden cardiac death: a distinct clinical and electrocardiographic syndrome: a multicenter report. J Am Coll Cardiol (1992) 20:1391-6. doi:10.1016/0735-1097(92)90253-J

2. Juang J-M, Huang SKS. Brugada syndrome - an under-recognized electrical disease in patients with sudden cardiac death. Cardiology (2004) 101:157-69. doi:10.1159/000076693

3. Papadakis M, Raju H, Behr ER, De Noronha SV, Spath N, Kouloubinis A, et al. Sudden cardiac death with autopsy findings of uncertain significance: potential for erroneous interpretation. Circ Arrhythm Electrophysiol (2013) 6:588-96. doi:10.1161/CIRCEP.113.000111

4. Wilde AAM, Antzelevitch C, Borggrefe M, Brugada J, Brugada R, Brugada $\mathrm{P}$, et al. Proposed diagnostic criteria for the Brugada syndrome: consensus report. Circulation (2002) 106:2514-9. doi:10.1161/01. CIR.0000034169.45752.4A

5. Antzelevitch C, Brugada P, Borggrefe M, Brugada J, Brugada R, Corrado D, et al. Brugada syndrome: report of the second consensus conference endorsed by the Heart Rhythm Society and the European Heart Rhythm Association. Circulation (2005) 111:659-70. doi:10.1161/01.CIR.0000152479.54298.51

6. Priori SG, Wilde AA, Horie M, Cho Y, Behr ER, Berul C, et al. HRS/EHRA/ APHRS expert consensus statement on the diagnosis and management of patients with inherited primary arrhythmia syndromes: document endorsed by HRS, EHRA, and APHRS in May 2013 and by ACCF, AHA, PACES, and AEPC in June 2013. Heart Rhythm (2013) 10:1932-63. doi:10.1016/j. hrthm.2013.05.014

7. Miyazaki T, Mitamura H, Miyoshi S, Soejima K, Aizawa Y, Ogawa S. Autonomic and antiarrhythmic drug modulation of ST segment elevation in patients with Brugada syndrome. J Am Coll Cardiol (1996) 27:1061-70. doi:10.1016/0735-1097(95)00613-3

8. Brugada R, Brugada J, Antzelevitch C, Kirsch GE, Potenza D, Towbin JA, et al. Sodium channel blockers identify risk for sudden death in patients with ST-segment elevation and right bundle branch block but structurally normal hearts. Circulation (2000) 101:510-5. doi:10.1161/01.CIR.101.5.510

9. Wolpert C, Echternach C, Veltmann C, Antzelevitch C, Thomas GP, Spehl S, et al. Intravenous drug challenge using flecainide and ajmaline in patients with Brugada syndrome. Heart Rhythm (2005) 2:254-60. doi:10.1016/j. hrthm.2004.11.025

10. Priori SG, Napolitano C, Gasparini M, Pappone C, Della Bella P, Giordano U, et al. Natural history of Brugada syndrome: insights for risk stratification and management. Circulation (2002) 105:1342-7. doi:10.1161/hc1102.105288

11. Gallagher MM, Forleo GB, Behr ER, Magliano G, De Luca L, Morgia V, et al. Prevalence and significance of Brugada-type ECG in 12,012 apparently healthy European subjects. Int J Cardiol (2008) 130:44-8. doi:10.1016/j. ijcard.2007.07.159
Retrospectively, SCN10A common variant identified in the BrS GWAS study have been also associated with the risk of VF in the context of myocardial infarction and with the pacemaker implantation rate $(103,104)$. Additionally, a protective role against developing AF has been suggested for both common variants previously identified as risk alleles for BrS at the SCN10ASCN5A locus. This reinforces the interest of rare diseases to help identifying the pathophysiological bases of common pathologies. As they constitute homogenous groups of patients, rare arrhythmia disorders can provide new molecular insights that may be relevant to the broader health issue of SCD (105).

\section{AUTHOR CONTRIBUTIONS}

All authors authored sections of the manuscript, contributed to the figure design, and approved the final version.

12. Miyasaka Y, Tsuji H, Yamada K, Tokunaga S, Saito D, Imuro Y, et al. Prevalence and mortality of the Brugada-type electrocardiogram in one city in Japan. J Am Coll Cardiol (2001) 38:771-4. doi:10.1016/S0735-1097(01)01419-X

13. Nademanee K, Veerakul G, Nimmannit S, Chaowakul V, Bhuripanyo K, Likittanasombat $\mathrm{K}$, et al. Arrhythmogenic marker for the sudden unexplained death syndrome in Thai men. Circulation (1997) 96:2595-600. doi:10.1161/01.CIR.96.8.2595

14. Probst V, Veltmann C, Eckardt L, Meregalli PG, Gaita F, Tan HL, et al. Longterm prognosis of patients diagnosed with Brugada syndrome: results from the FINGER Brugada Syndrome Registry. Circulation (2010) 121:635-43. doi:10.1161/CIRCULATIONAHA.109.887026

15. Benito B, Sarkozy A, Mont L, Henkens S, Berruezo A, Tamborero D, et al. Gender differences in clinical manifestations of Brugada syndrome. J Am Coll Cardiol (2008) 52:1567-73. doi:10.1016/j.jacc.2008.07.052

16. Sacher F, Arsac F, Wilton SB, Derval N, Denis A, de Guillebon M, et al. Syncope in Brugada syndrome patients: prevalence, characteristics, and outcome. Heart Rhythm (2012) 9:1272-9. doi:10.1016/j.hrthm.2012.04.013

17. Take $Y$, Morita $H$, Toh N, Nishii N, Nagase S, Nakamura K, et al. Identification of high-risk syncope related to ventricular fibrillation in patients with Brugada syndrome. Heart Rhythm (2012) 9:752-9. doi:10.1016/j.hrthm.2011.11.045

18. Sacher F, Probst V, Maury P, Babuty D, Mansourati J, Komatsu Y, et al. Outcome after implantation of a cardioverter-defibrillator in patients with Brugada syndrome: a multicenter study-part 2. Circulation (2013) 128:1739-47. doi:10.1161/CIRCULATIONAHA.113.001941

19. Sarkozy A, Boussy T, Kourgiannides G, Chierchia GB, Richter S, De Potter T, et al. Long-term follow-up of primary prophylactic implantable cardioverter-defibrillator therapy in Brugada syndrome. Eur Heart J (2007) 28:334-44. doi:10.1093/eurheartj/ehm478

20. Priori SG, Gasparini M, Napolitano C, Della Bella P, Ottonelli AG, Sassone $B$, et al. Risk stratification in Brugada syndrome: results of the PRELUDE (PRogrammed ELectrical stimUlation preDictive valuE) registry. J Am Coll Cardiol (2012) 59:37-45. doi:10.1016/j.jacc.2011.08.064

21. Conte G, Sieira J, Ciconte G, de Asmundis C, Chierchia GB, Baltogiannis G, et al. Implantable cardioverter-defibrillator therapy in Brugada syndrome: a 20-year single-center experience. J Am Coll Cardiol (2015) 65:879-88. doi:10.1016/j.jacc.2014.12.031

22. Sroubek J, Probst V, Mazzanti A, Delise P, Hevia JC, Ohkubo K, et al. Programmed ventricular stimulation for risk stratification in the Brugada syndrome: a pooled analysis. Circulation (2016) 133:622-30. doi:10.1161/ CIRCULATIONAHA.115.017885

23. Probst V, Chatel S, Gourraud J-B, Marec HL. Risk stratification and therapeutic approach in Brugada syndrome. Arrhythm Electrophysiol Rev (2012) 1:17-21. doi:10.15420/aer.2012.1.1.17

24. Belhassen B, Viskin S, Fish R, Glick A, Setbon I, Eldar M. Effects of electrophysiologic-guided therapy with Class IA antiarrhythmic drugs on the long-term outcome of patients with idiopathic ventricular fibrillation 
with or without the Brugada syndrome. J Cardiovasc Electrophysiol (1999) 10:1301-12. doi:10.1111/j.1540-8167.1999.tb00183.x

25. Hermida JS, Denjoy I, Clerc J, Extramiana F, Jarry G, Milliez P, et al. Hydroquinidine therapy in Brugada syndrome. J Am Coll Cardiol (2004) 43:1853-60. doi:10.1016/j.jacc.2003.12.046

26. Belhassen B, Glick A, Viskin S. Efficacy of quinidine in high-risk patients with Brugada syndrome. Circulation (2004) 110:1731-7. doi:10.1161/01. CIR.0000143159.30585.90

27. Probst V, Gourraud J-B. Quinidine in Brugada syndrome: still a long way to go.... Circ Arrhythm Electrophysiol (2015) 8:1309-10. doi:10.1161/ CIRCEP.115.003576

28. Adler A, Rosso R, Chorin E, Havakuk O, Antzelevitch C, Viskin S. Risk stratification in Brugada syndrome: clinical characteristics, electrocardiographic parameters, and auxiliary testing. Heart Rhythm (2016) 13:299-310. doi:10.1016/j.hrthm.2015.08.038

29. Yan G-X, Antzelevitch C. Cellular basis for the electrocardiographic J wave. Circulation (1996) 93:372-9. doi:10.1161/01.CIR.93.2.372

30. Diego JMD, Sun ZQ, Antzelevitch C. I(to) and action potential notch are smaller in left vs. right canine ventricular epicardium. Am J Physiol (1996) 271:H548-61.

31. Fujiki A, Usui M, Nagasawa H, Mizumaki K, Hayashi H, Inoue H. ST segment elevation in the right precordial leads induced with Class IC antiarrhythmic drugs: insight into the mechanism of Brugada syndrome. J Cardiovasc Electrophysiol (1999) 10:214-8. doi:10.1111/j.1540-8167.1999.tb00662.x

32. Nagase S, Kusano KF, Morita H, Fujimoto Y, Kakishita M, Nakamura K, et al. Epicardial electrogram of the right ventricular outflow tract in patients with the Brugada syndrome: using the epicardial lead. J Am Coll Cardiol (2002) 39:1992-5. doi:10.1016/S0735-1097(02)01888-0

33. Tukkie R, Sogaard P, Vleugels J, de Groot IK, Wilde AA, Tan HL. Delay in right ventricular activation contributes to Brugada syndrome. Circulation (2004) 109:1272-7. doi:10.1161/01.CIR.0000118467.53182.D1

34. Wilde AA, Postema PG, Di Diego JM, Viskin S, Morita H, Fish JM, et al. The pathophysiological mechanism underlying Brugada syndrome: depolarization versus repolarization. J Mol Cell Cardiol (2010) 49:543-53. doi:10.1016/j. yjmcc.2010.07.012

35. Boukens BJ, Sylva M, de Gier-de Vries C, Remme CA, Bezzina CR, Christoffels $\mathrm{VM}$, et al. Reduced sodium channel function unmasks residual embryonic slow conduction in the adult right ventricular outflow tract. Circ Res (2013) 113:137-41. doi:10.1161/CIRCRESAHA.113.301565

36. Watanabe H, Minamino T. Genetics of Brugada syndrome. J Hum Genet (2016) 61:57-60. doi:10.1038/jhg.2015.97

37. Spoonamore KG, Ware SM. Genetic testing and genetic counseling in patients with sudden death risk due to heritable arrhythmias. Heart Rhythm (2016) 13:789-97. doi:10.1016/j.hrthm.2015.11.013

38. Kobayashi $T$, Shintani U, Yamamoto $T$, Shida $S$, Isshiki N, Tanaka $T$, et al. Familial occurrence of electrocardiographic abnormalities of the Brugada-type. Intern Med (1996) 35:637-40. doi:10.2169/internalmedicine. 35.637

39. Garg A, Finneran W, Feld GK. Familial sudden cardiac death associated with a terminal QRS abnormality on surface 12-lead electrocardiogram in the index case. JCardiovasc Electrophysiol (1998) 9:642-7. doi:10.111 1/j.1540-8167.1998.tb00947.x

40. Brugada P, Brugada R, Brugada J. Sudden death in patients and relatives with the syndrome of right bundle branch block, ST segment elevation in the precordial leads V1to V3and sudden death. Eur Heart J (2000) 21:321-6. doi:10.1053/euhj.1999.1751

41. Probst V, Wilde AA, Barc J, Sacher F, Babuty D, Mabo P, et al. SCN5A mutations and the role of genetic background in the pathophysiology of Brugada syndrome. Circ Cardiovasc Genet (2009) 2:552-7. doi:10.1161/ CIRCGENETICS.109.853374

42. Chen Q, Kirsch GE, Zhang D, Brugada R, Brugada J, Brugada P, et al. Genetic basis and molecular mechanism for idiopathic ventricular fibrillation. Nature (1998) 392:293-6. doi:10.1038/33305

43. Crotti L, Marcou CA, Tester DJ, Castelletti S, Giudicessi JR, Torchio M, et al. Spectrum and prevalence of mutations involving BrS1- through BrS12susceptibility genes in a cohort of unrelated patients referred for Brugada syndrome genetic testing: implications for genetic testing. J Am Coll Cardiol (2012) 60:1410-8. doi:10.1016/j.jacc.2012.04.037
44. Le Scouarnec S, Karakachoff M, Gourraud JB, Lindenbaum P, Bonnaud $\mathrm{S}$, Portero V, et al. Testing the burden of rare variation in arrhythmia-susceptibility genes provides new insights into molecular diagnosis for Brugada syndrome. Hum Mol Genet (2015) 24:2757-63. doi:10.1093/ hmg/ddv036

45. Andorin A, et al. The impact of clinical and genetic findings on the management of young Brugada syndrome patients. Heart Rhythm (2016). doi:10.1016/j.hrthm.2016.02.013

46. Sommariva E, Pappone C, Martinelli Boneschi F, Di Resta C, Rosaria Carbone $\mathrm{M}$, Salvi E, et al. Genetics can contribute to the prognosis of Brugada syndrome: a pilot model for risk stratification. Eur J Hum Genet (2013) 21:911-7. doi:10.1038/ejhg.2012.289

47. Meregalli PG, Tan HL, Probst V, Koopmann TT, Tanck MW, Bhuiyan ZA, et al. Type of SCN5A mutation determines clinical severity and degree of conduction slowing in loss-of-function sodium channelopathies. Heart Rhythm (2009) 6:341-8. doi:10.1016/j.hrthm.2008.11.009

48. Nishii N, Ogawa M, Morita H, Nakamura K, Banba K, Miura D, et al. SCN5A mutation is associated with early and frequent recurrence of ventricular fibrillation in patients with Brugada syndrome. Circ J (2010) 74:2572-8. doi:10.1253/circj.CJ-10-044

49. London B, Michalec M, Mehdi H, Zhu X, Kerchner L, Sanyal S, et al. Mutation in glycerol-3-phosphate dehydrogenase 1 like gene (GPD1-L) decreases cardiac $\mathrm{Na}+$ current and causes inherited arrhythmias. Circulation (2007) 116:2260-8. doi:10.1161/CIRCULATIONAHA.107.703330

50. Fukuda K, Davies SS, Nakajima T, Ong BH, Kupershmidt S, Fessel J, et al. Oxidative mediated lipid peroxidation recapitulates proarrhythmic effects on cardiac sodium channels. Circ Res (2005) 97:1262-9. doi:10.1161/01. RES.0000195844.31466.e9

51. Antzelevitch C, Pollevick GD, Cordeiro JM, Casis O, Sanguinetti MC, Aizawa $\mathrm{Y}$, et al. Loss-of-function mutations in the cardiac calcium channel underlie a new clinical entity characterized by ST-segment elevation, short QT intervals, and sudden cardiac death. Circulation (2007) 115:442-9. doi:10.1161/ CIRCULATIONAHA.106.668392

52. Watanabe H, Koopmann TT, Le Scouarnec S, Yang T, Ingram CR, Schott JJ, et al. Sodium channel $\beta 1$ subunit mutations associated with Brugada syndrome and cardiac conduction disease in humans. J Clin Invest (2008) 118:2260-8. doi:10.1172/JCI33891

53. Delpón E, Cordeiro JM, Núñez L, Thomsen PE, Guerchicoff A, Pollevick GD, et al. Functional effects of KCNE3 mutation and its role in the development of Brugada syndrome. Circ Arrhythm Electrophysiol (2008) 1:209-18. doi:10.1161/CIRCEP.107.748103

54. Hu D, Barajas-Martinez H, Burashnikov E, Springer M, Wu Y, Varro A, et al. A mutation in the $\beta 3$ subunit of the cardiac sodium channel associated with Brugada ECG phenotype. Circ Cardiovasc Genet (2009) 2:270-8. doi:10.1161/ CIRCGENETICS. 108.829192

55. Ueda K, Hirano Y, Higashiuesato Y, Aizawa Y, Hayashi T, Inagaki N, et al. Role of HCN4 channel in preventing ventricular arrhythmia. J Hum Genet (2009) 54:115-21. doi:10.1038/jhg.2008.16

56. Giudicessi JR, Ye D, Tester DJ, Crotti L, Mugione A, Nesterenko VV, et al. Transient outward current (I(to)) gain-of-function mutations in the KCND3encoded Kv4.3 potassium channel and Brugada syndrome. Heart Rhythm (2011) 8:1024-32. doi:10.1016/j.hrthm.2011.02.021

57. Medeiros-Domingo A, Tan BH, Crotti L, Tester DJ, Eckhardt L, Cuoretti A, et al. Gain-of-function mutation S422L in the KCNJ8-encoded cardiac KATP channel Kir6.1 as a pathogenic substrate for J-wave syndromes. Heart Rhythm (2010) 7:1466-71. doi:10.1016/j.hrthm.2010.06.016

58. Burashnikov E, Pfeiffer R, Barajas-Martinez H, Delpón E, Hu D, Desai $\mathrm{M}$, et al. Mutations in the cardiac L-type calcium channel associated with inherited J-wave syndromes and sudden cardiac death. Heart Rhythm (2010) 7:1872-82. doi:10.1016/j.hrthm.2010.08.026

59. Ohno S, Zankov DP, Ding WG, Itoh H, Makiyama T, Doi T, et al. KCNE5 (KCNE1L) variants are novel modulators of Brugada syndrome and idiopathic ventricular fibrillation. Circ Arrhythm Electrophysiol (2011) 4:352-61. doi:10.1161/CIRCEP.110.959619

60. Olesen MS, Jensen NF, Holst AG, Nielsen JB, Tfelt-Hansen J, Jespersen T, et al. A novel nonsense variant in Nav1.5 cofactor MOG1 eliminates its sodium current increasing effect and may increase the risk of arrhythmias. Can J Cardiol (2011) 27:e17-23. doi:10.1016/j.cjca.2011.01.003 
61. Perrin MJ, Adler A, Green S, Al-Zoughool F, Doroshenko P, Orr N, et al. Evaluation of genes encoding for the transient outward current (Ito) identifies the KCND2 gene as a cause of J-wave syndrome associated with sudden cardiac death. Circ Cardiovasc Genet (2014) 7:782-9. doi:10.1161/ CIRCGENETICS.114.000623

62. Liu H, Chatel S, Simard C, Syam N, Salle L, Probst V, et al. Molecular genetics and functional anomalies in a series of 248 Brugada cases with 11 mutations in the TRPM4 channel. PLoS One (2013) 8:e54131. doi:10.1371/journal. pone. 0054131

63. Riuró H, Beltran-Alvarez P, Tarradas A, Selga E, Campuzano O, Vergés M, et al. A missense mutation in the sodium channel $\beta 2$ subunit reveals SCN2B as a new candidate gene for Brugada syndrome. Hum Mutat (2013) 34:961-6. doi:10.1002/humu.22328

64. Cerrone M, Lin X, Zhang M, Agullo-Pascual E, Pfenniger A, Chkourko Gusky $\mathrm{H}$, et al. Missense mutations in plakophilin-2 cause sodium current deficit and associate with a Brugada syndrome phenotype. Circulation (2014) 129:1092-103. doi:10.1161/CIRCULATIONAHA.113.003077

65. Hu D, Barajas-Martínez H, Terzic A, Park S, Pfeiffer R, Burashnikov E, et al. ABCC9 is a novel Brugada and early repolarization syndrome susceptibility gene. Int J Cardiol (2014) 171:431-42. doi:10.1016/j.ijcard.2013.12.084

66. Ishikawa T, Sato A, Marcou CA, Tester DJ, Ackerman MJ, Crotti L, et al. A novel disease gene for Brugada syndrome: sarcolemmal membrane-associated protein gene mutations impair intracellular trafficking of hNav1.5. Circ Arrhythm Electrophysiol (2012) 5:1098-107. doi:10.1161/CIRCEP. 111.969972

67. Wang Q, Ohno S, Ding WG, Fukuyama M, Miyamoto A, Itoh H, et al. Gain-of-function KCNH2 mutations in patients with Brugada syndrome. J Cardiovasc Electrophysiol (2014) 25:522-30. doi:10.1111/jce.12361

68. Hu D, Barajas-Martínez H, Pfeiffer R, Dezi F, Pfeiffer J, Buch T, et al. Mutations in SCN10A are responsible for a large fraction of cases of Brugada syndrome. J Am Coll Cardiol (2014) 64:66-79. doi:10.1016/j.jacc.2014. 04.032

69. Behr ER, Savio-Galimberti E, Barc J, Holst AG, Petropoulou E, Prins BP, et al. Role of common and rare variants in SCN10A: results from the Brugada syndrome QRS locus gene discovery collaborative study. Cardiovasc Res (2015) 106:520-9. doi:10.1093/cvr/cvv042

70. Hennessey JA, Marcou CA, Wang C, Wei EQ, Wang C, Tester DJ, et al. FGF12 is a candidate Brugada syndrome locus. Heart Rhythm (2013) 10:1886-94. doi:10.1016/j.hrthm.2013.09.064

71. Boczek NJ, Ye D, Johnson EK, Wang W, Crotti L, Tester DJ, et al. Characterization of SEMA3A-encoded semaphorin as a naturally occurring Kv4.3 protein inhibitor and its contribution to Brugada syndrome. Circ Res (2014) 115:460-9. doi:10.1161/CIRCRESAHA.115.303657

72. Brenner S, Johnson M, Bridgham J, Golda G, Lloyd DH, Johnson D, et al. Gene expression analysis by massively parallel signature sequencing (MPSS) on microbead arrays. Nat Biotechnol (2000) 18:630-4. doi:10.1038/76469

73. Porreca GJ, Zhang K, Li JB, Xie B, Austin D, Vassallo SL, et al. Multiplex amplification of large sets of human exons. Nat Methods (2007) 4:931-6. doi:10.1038/nmeth1110

74. Margulies M, Egholm M, Altman WE, Attiya S, Bader JS, Bemben LA, et al. Genome sequencing in microfabricated high-density picolitre reactors. Nature (2005) 437:376-80. doi:10.1038/nature03959

75. Tennessen JA, Bigham AW, O'Connor TD, Fu W, Kenny EE, Gravel S, et al. Evolution and functional impact of rare coding variation from deep sequencing of human exomes. Science (2012) 337:64-9. doi:10.1126/science.1219240

76. Fu W, O'Connor TD, Jun G, Kang HM, Abecasis G, Leal SM, et al. Analysis of 6,515 exomes reveals the recent origin of most human protein-coding variants. Nature (2013) 493:216-20. doi:10.1038/nature11690

77. Venter JC, Adams MD, Myers EW, Li PW, Mural RJ, Sutton GG, et al. The sequence of the human genome. Science (2001) 291:1304-51. doi:10.1126/ science. 1058040

78. Lander ES, Linton LM, Birren B, Nusbaum C, Zody MC, Baldwin J, et al. Initial sequencing and analysis of the human genome. Nature (2001) 409:860-921. doi:10.1038/35057062

79. Tabor HK, Auer PL, Jamal SM, Chong JX, Yu JH, Gordon AS, et al. Pathogenic variants for Mendelian and complex traits in exomes of 6,517 European and African Americans: implications for the return of incidental results. Am J Hum Genet (2014) 95:183-93. doi:10.1016/j.ajhg.2014.07.006
80. Amendola LM, Dorschner MO, Robertson PD, Salama JS, Hart R, Shirts $\mathrm{BH}$, et al. Actionable exomic incidental findings in 6503 participants: challenges of variant classification. Genome Res (2015) 25:305-15. doi:10.1101/ gr.183483.114

81. Van Driest SL, Wells QS, Stallings S, Bush WS, Gordon A, Nickerson DA, et al. Association of arrhythmia-related genetic variants with phenotypes documented in electronic medical records. JAMA (2016) 315:47-57. doi:10.1001/jama.2015.17701

82. Ackerman MJ. Genetic purgatory and the cardiac channelopathies: exposing the variants of uncertain/unknown significance issue. Heart Rhythm (2015) 12:2325-31. doi:10.1016/j.hrthm.2015.07.002

83. Risgaard B, Jabbari R, Refsgaard L, Holst AG, Haunsø S, Sadjadieh A, et al. High prevalence of genetic variants previously associated with Brugada syndrome in new exome data. Clin Genet (2013) 84:489-95. doi:10.1111/ cge. 12126

84. Akopian AN, Sivilotti L, Wood JN. A tetrodotoxin-resistant voltage-gated sodium channel expressed by sensory neurons. Nature (1996) 379:257-62. doi:10.1038/379257a0

85. Renganathan M, Cummins TR, Waxman SG. Contribution of $\mathrm{Na}(\mathrm{v}) 1.8$ sodium channels to action potential electrogenesis in DRG neurons. J Neurophysiol (2001) 86:629-40.

86. Pallante BA, Giovannone S, Fang-Yu L, Zhang J, Liu N, Kang G, et al. Contactin-2 expression in the cardiac Purkinje fiber network. Circ Arrhythm Electrophysiol (2010) 3:186-94. doi:10.1161/CIRCEP.109.928820

87. Yang T, Atack TC, Stroud DM, Zhang W, Hall L, Roden DM. Blocking Scn10a channels in heart reduces late sodium current and is antiarrhythmic. Circ Res (2012) 111:322-32. doi:10.1161/CIRCRESAHA.112.265173

88. Kapa S, Tester DJ, Salisbury BA, Harris-Kerr C, Pungliya MS, Alders M, et al. Genetic testing for long-QT syndrome distinguishing pathogenic mutations from benign variants. Circulation (2009) 120:1752-60. doi:10.1161/ CIRCULATIONAHA.109.863076

89. Kumar P, Henikoff S, Ng PC. Predicting the effects of coding non-synonymous variants on protein function using the SIFT algorithm. Nat Protoc (2009) 4:1073-81. doi:10.1038/nprot.2009.86

90. Adzhubei IA, Schmidt S, Peshkin L, Ramensky VE, Gerasimova A, Bork P, et al. A method and server for predicting damaging missense mutations. Nat Methods (2010) 7:248-9. doi:10.1038/nmeth0410-248

91. Antzelevitch C. J wave syndromes: molecular and cellular mechanisms. J Electrocardiol (2013) 46:510-8. doi:10.1016/j.jelectrocard.2013.08.006

92. Watanabe $\mathrm{H}$, Minamino T. Role of mutations in L-type calcium channel genes in Brugada syndrome, early repolarization syndrome, and idiopathic ventricular fibrillation associated with right bundle branch block. Circ J (2013) 77:1689-90. doi:10.1253/circj.CJ-13-0641

93. Kapplinger JD, Tester DJ, Alders M, Benito B, Berthet M, Brugada J, et al. An international compendium of mutations in the SCN5A-encoded cardiac sodium channel in patients referred for Brugada syndrome genetic testing. Heart Rhythm (2010) 7:33-46. doi:10.1016/j.hrthm.2009.09.069

94. Schott JJ, Alshinawi C, Kyndt F, Probst V, Hoorntje TM, Hulsbeek M, et al. Cardiac conduction defects associate with mutations in SCN5A. Nat Genet (1999) 23:20-1. doi:10.1038/12618

95. Kyndt F, Probst V, Potet F, Demolombe S, Chevallier JC, Baro I, et al. Novel SCN5A mutation leading either to isolated cardiac conduction defect or Brugada syndrome in a large French family. Circulation (2001) 104:3081-6. doi:10.1161/hc5001.100834

96. Bezzina C, Veldkamp MW, van Den Berg MP, Postma AV, Rook MB, Viersma $\mathrm{JW}$, et al. A single Na+ channel mutation causing both long-QT and Brugada syndromes. Circ Res (1999) 85:1206-13. doi:10.1161/01.RES.85.12.1206

97. Pfeufer A, van Noord C, Marciante KD, Arking DE, Larson MG, Smith $\mathrm{AV}$, et al. Genome-wide association study of PR interval. Nat Genet (2010) 42:153-9. doi:10.1038/ng.517

98. van den Boogaard M, Wong LY, Tessadori F, Bakker ML, Dreizehnter LK, Wakker V, et al. Genetic variation in T-box binding element functionally affects SCN5A/SCN10A enhancer. JClin Invest (2012) 122:2519-30. doi:10.1172/JCI62613

99. van den Boogaard M, Smemo S, Burnicka-Turek O, Arnolds DE, van de Werken HJ, Klous P, et al. A common genetic variant within SCN10A modulates cardiac SCN5A expression. JClin Invest (2014) 124:1844-52. doi:10.1172/JCI73140 
100. Reamon-Buettner SM, Borlak J. HEY2 mutations in malformed hearts. Hum Mutat (2006) 27:118. doi:10.1002/humu.9390

101. Bezzina CR, Barc J, Mizusawa Y, Remme CA, Gourraud JB, Simonet F, et al. Common variants at SCN5A-SCN10A and HEY2 are associated with Brugada syndrome, a rare disease with high risk of sudden cardiac death. Nat Genet (2013) 45:1044-9. doi:10.1038/ng.2712

102. Nakano Y, Ochi H, Onohara Y, Toshishige M, Tokuyama T, Matsumura $\mathrm{H}$, et al. Common variant near HEY2 has a protective effect on ventricular fibrillation occurrence in Brugada syndrome by regulating the repolarization current. Circ Arrhythm Electrophysiol (2016) 9. doi:10.1161/CIRCEP. 115.003436

103. Bezzina CR, Pazoki R, Bardai A, Marsman RF, de Jong JS, Blom MT, et al. Genome-wide association study identifies a susceptibility locus at 21q21 for ventricular fibrillation in acute myocardial infarction. Nat Genet (2010) 42:688-91. doi:10.1038/ng.623

104. Holm H, Gudbjartsson DF, Arnar DO, Thorleifsson G, Thorgeirsson G, Stefansdottir $\mathrm{H}$, et al. Several common variants modulate heart rate,
PR interval and QRS duration. Nat Genet (2010) 42:117-22. doi:10.1038/ ng.511

105. Andreasen L, Nielsen JB, Darkner S, Christophersen IE, Jabbari J, Refsgaard L, et al. Brugada syndrome risk loci seem protective against atrial fibrillation. Eur J Hum Genet (2014) 22:1357-61. doi:10.1038/ejhg.2014.46

Conflict of Interest Statement: The authors declare that the research was conducted in the absence of any commercial or financial relationships that could be construed as a potential conflict of interest.

Copyright $\odot 2016$ Gourraud, Barc, Thollet, Le Scouarnec, Le Marec, Schott, Redon and Probst. This is an open-access article distributed under the terms of the Creative Commons Attribution License (CC BY). The use, distribution or reproduction in other forums is permitted, provided the original author(s) or licensor are credited and that the original publication in this journal is cited, in accordance with accepted academic practice. No use, distribution or reproduction is permitted which does not comply with these terms. 